\title{
Little-used medical technology could help thousands see, hear and feel better
}

'If you look hard and long, you can find us. If you listen hard and long, you can hear any of us, call any of us that you wish.'

(Tamora Pierce, Wild Magic)

South Africa (SA) has the home-grown expertise and technology to drastically improve the eyesight, hearing and nutrition of most of the tens of thousands of its citizens who suffer unnecessarily from severe impairment in these areas.

That's the inescapable conclusion Izindaba came to after tracking down and interviewing four of the country's leading innovators in these fields. Their highly mobile, cost-saving, ground-breaking devices and adaptable products are only now gaining slow purchase after languishing for years in the backwaters of resistance, suspicion and bureaucratic apathy.

\section{Hearing}

A dramatic diagnostic innovation is a device called the KUDUwave 5000 Portable Diagnostic Audiometer, which detects impending partial or total hearing loss suffered by (among other patient groups) between $30 \%$ and $47 \%$ of people undergoing treatment for multidrugresistant tuberculosis (MDR-TB) (about 10000 at present). ${ }^{[1]}$ The existing MDR-TB hearing loss percentages translate to about 4000 people 


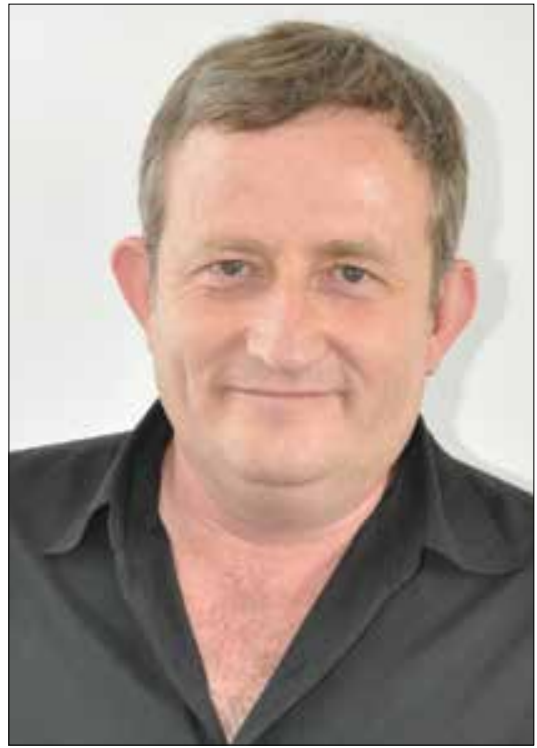

Medical device innovator Dr Dirk Koekemoer.

on the verge of mild to profound hearing loss as a result of side-effects of the toxic but lifesaving kanamycin, a drug used in the MDRTB treatment cocktail. With the new alternative MDR-TB drug bedaquiline now being cautiously and slowly rolled out to decentralised MDR-TB treatment clinics nationwide, the timely use of a portable audiometer to diagnose early hearing loss enables a drug switch with far better outcomes. The cost of surviving MDR$\mathrm{TB}$ before bedaquiline and another effective new MDR-TB drug delamanid (the first new TB drugs in 40 years) became available this year was a near-even chance of mild to profound hearing loss - if the patient was among the estimated $48 \%$ who survived MDR-TB at all. Hundreds of the surviving MDR-TB patients remain at risk of imminent deafness due to the (some clinicians say overly) cautious roll-out of bedaquiline - and the National Drug-Resistant TB Directorate's financially conservative purchase of just 120 portable audiometers (which cost ZAR45 000 each, excluding VAT, as opposed to ZAR250 000 for existing sparsely distributed stationary audio booths). There are 4500 primary healthcare clinics in SA, with 350 either treating MDR-TB or being set up to do so.

The audiometer is light and portable (carried in a small suitcase, it consists of a headset, computer tablet and software), and can detect ototoxicity by measuring the ear's ability to detect very high frequencies. It is best used in an open space (as opposed to the closed traditional booth), an additional benefit given the airborne cross-patient infectiousness of MDR-TB. The data can be transmitted directly by a nurse with basic proficiency via easy training or an audiometrist to an audiologist, who can interpret, properly diagnose, and recommend or adjust treatment. Far from taking work away from specialists it will probably create more, but vastly improve efficiency and increase the number of diagnoses.

Medical device innovator, medical doctor and software developer Dirk Koekemoer believes that his device (should the national health department quickly expand its current pilot project to all existing clinics) has the potential to save the hearing of at least 2000 MDR-TBinfected people. 'If you pick up the ototoxicity, you can stop the meds [kanamycin] immediately and save their hearing - it's all about how well you can apply the KUDUwave and thus identify the kanamycin toxicity. There are about 1600 audiologists in SA; of these about 400 work in the public sector, creating a heavy workload. Koekemoer said that deafness is the most common chronic disability in the world, with an estimated 3 million South Africans needing hearing aids and other hearing services, for all sorts of reasons. 'I think they should have bought 250 KUDUwaves at the outset - I mean I have 200 just lying here now, but Dr Norbert Ndjeka [MDR-TB Directorate chief] needs to motivate and get a budget passed - there's simply nobody else in the world with similar equipment,' he emphasised.

\section{Engineer, medical technologist} and software developer Dirk

Koekemoer believes that his device (should the national health department quickly expand its current pilot project to all existing clinics) has the potential to save the hearing of at least $2000 \mathrm{MDR}$ TB-infected people.

Since realising during testing in 2006 that he had 16 medical devices that could examine a patient 'better than a GP - and automate primary healthcare from screening to diagnostics and treatment', he's had his share of frustrations. 'You develop something, work out how to do things, market this new principle, process and equipment to government - and in the end they [seem to] understand it. Then they put out a tender for traditional equipment - and you don't get the tender. I've learnt to identify the champions in government and seed them - then they finally go for it. Otherwise you have to find the money yourself through NGOs.' Illustrating the utility of the device, he said there was one audiologist in Zambia using his devices to fit hearing aids and assist 'thousands of people via the internet'. 'The impact is huge, not just from a humanitarian perspective but also on the professionals that use the equipment'. One 'now massive' private practice in SA had 20 units distributed via small-town pharmacies across the country. 'All I know is that there are 350 decentralised [public sector] TB sites going up across the country and each one needs one.' Koekemoer said that on 24 March (World TB Day) this year, he watched with government officials as 250 self-selected patients 'self-screened' (under supervision) on the KUDUwave in Kanana township near Orkney in North West Province over a 4-hour period. A total of 40 were automatically referred to an audiologist (via an SMS to their phone)

\section{Nutrition}

The National Department of Health introduced an integrated nutrition programme in 1995 to counter, among other things, the partly HIVdriven $11.4 \%$ of deaths of SA children under 5 years old attributed to low birth weight. ${ }^{[2,3]}$ However, there have been copious challenges and widely varying success rates, and an estimated $15 \%$ of infants are still being born with a low birth weight. This is in spite of the massive and sustained roll-out of antiretroviral (ARV) drugs, which has dramatically slowed HIV incidence. Resistance to breastfeeding remains widespread (before the hugely successful introduction of prevention of mother-to-child transmission (PMTC) drugs, breastfeeding was the surest way of transmitting HIV to your child). Providing proper nutrition to anyone undergoing ARV treatment is vital, given that drug-induced nausea can cause vomiting and reduce overall food intake. Overall, the most easily preventable yet most prominent detrimental health conditions associated with malnutrition are nutrient deficiencies. The impact of anaemia caused by low iron levels among preschool children (21.4\%) and pregnant women (50\%), ${ }^{[2,3]}$ and of deficiencies in various vitamins and calcium (causing visual impairment/blindness and beriberi, respectively), is overwhelming. ${ }^{[4]}$ UNICEF puts the main causes of malnutrition

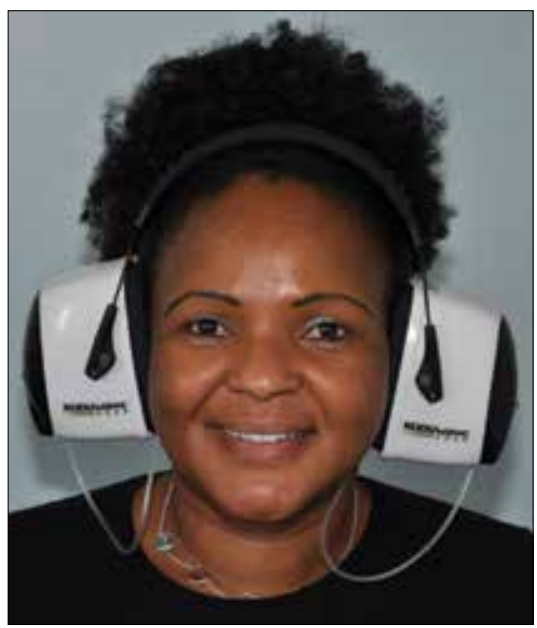

The KUDUwave portable audiometer. 
down to 'household food insecurity, inadequate child and maternal care, and insufficient essential human services such as health, education, water and environmental sanitation and housing.

\section{Not only does surgical removal of cataracts improve the self-care and potential earning capacity of the mostly elderly patients,} but the impact on HIV/AIDSorphaned children is enormous. In SA each elderly caregiver looks after an estimated average of 4.6 children.

Enter Profs Spinnler Benade and Maretha Opperman, head and vice-head of the Cape Peninsula University of Technology's Functional Food Research Unit. With several patented nutritional supplements to their name, they now have a formulation in biscuit and porridge form that addresses specific nutritional deficiencies in vulnerable SA populations. Working backwards from the epidemiological data, they've come up with a premix of red palm oil-derived beta-carotene and five different forms of vitamin $\mathrm{E}$ and vital minerals. The $25 \mathrm{~g}$ biscuit is aimed at children up to the age of 5 , and the porridge at any older vulnerable person. Public funding would enable quick and effective free distribution to vulnerable groups (pregnant women and children). Already some goldmines have expressed interest in on-site distribution of the porridge to their workers. Unpublished clinical trials involving 80 preschool children in Bethelsdorp near Port Elizabeth, with the biscuit being administered once daily, five days a week for 6 months, have shown dramatic and unprecedented drops in vitamin $\mathrm{E}$ deficiencies. Opperman says that the prevalence of vitamin $\mathrm{E}$ deficiencies was unexpected in this group. 'Vitamin E is essential for weight gain, optimal growth and development of the nervous system, and because of poor diets low in fruit, vegetables and healthy oils, vitamin E deficiency is a reality?

She added: 'We know the biscuit and porridge concept works, as has been proven in several clinical trials - this model provides an excellent opportunity for government and the private sector to become involved to address these nutrition problems in disadvantaged communities. The long-term effects of such an involvement by different stakeholders could be a good investment in terms of health, nutrition and development.'

\section{Seeing}

Sixteen months into his Stellenbosch University ophthalmology registration, Dr Will Mapham, his generalist skills honed in the public sector healthcare cauldron of the Eastern Cape's deep rural hospitals and now working at Tygerberg Hospital, has come up with a versatile eyetest cell-phone application. It will turbo-charge referral times and improve diagnoses and treatment, especially for its target patient group, far-flung, mostly indigent rural people.

The Vula Eye Health mobile app enables health workers to conduct eye tests, take an accurate history and photos of the eyes, and communicate with specialists via its 'eyeMessage' system, hugely assisting appropriate referrals. ${ }^{[5]}$ It doesn't take much to imagine its potential when you witness the impact of cataract surgery on sight restoration and a person's life - given that cataracts cause $66 \%$ of all blindness in SA (the incidence of blindness due to cataracts is calculated at 1000 people per year, $80 \%$ of whom are indigent). Not only does surgical removal of cataracts improve the selfcare and potential earning capacity of the mostly elderly patients, but the impact on HIV/AIDSorphaned children is enormous. In SA each elderly caregiver looks after an estimated average of 4.6 children, while in Zimbabwe about $71 \%$ of grandparents older than 60 years care for HIV/ AIDS-orphaned children.

Mapham has intimate knowledge of what a difference near-gold-standard annual cataract surgery rates make. He was a referring medical officer to Port Elizabeth Provincial Hospital's Drs Mark Jacoby and Danie Louw, who have since come to within a few dozen of the international gold-standard cataract surgery rate of 2000 surgical procedures per 1 million blind people. ${ }^{[6]}$ (The SA downward-revised local target is 1500 , set in 2010 when research showed that most units were failing even to get close to this level.) A measure of the PE surgical pair's success is that their cataract patient profile has changed from mostly blinding cataracts to early cataracts requiring a less invasive procedure with quicker healing and similar quality of restored sight. This strongly underlines the value of Mapham's cell-phone referral application. Mapham first made his name as a young medical officer when he helped recruit dozens of interns, community service doctors and medical officers to less popular deep rural Eastern Cape coastal area rural hospitals by touting the benefits of the unique generalist learning curve and unmatched rural leisure lifestyle on campuses and at major medical events. ${ }^{[7]}$ His cell-phone app was made possible by a R1 million South African Breweries research grant to develop, programme, test, market and explore high-tech innovations. In 2008 he published 'Mobile phones: Changing healthcare one SMS at a time ${ }^{[[5]}$ in the $S A$ Journal of HIV Medicine. He says that his inspiration for the app came from working

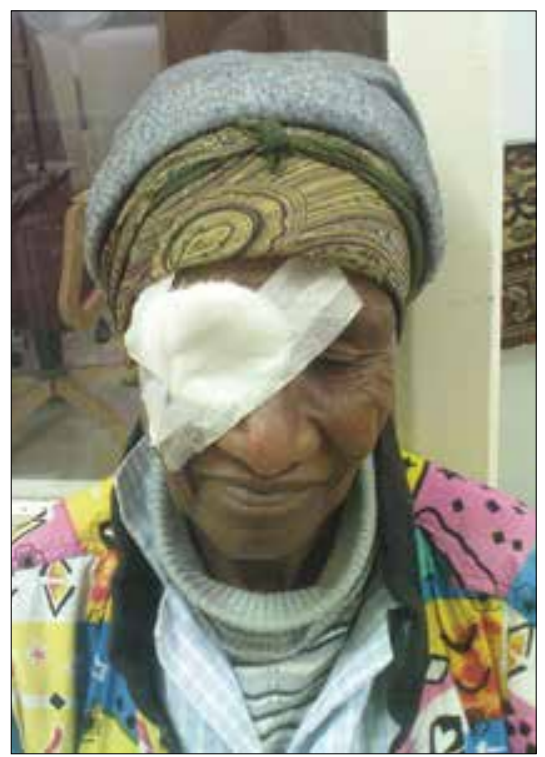

A victim of blinding cataract will soon see again.

in the Eastern Cape and Swaziland, ${ }^{[8]}$ where people had limited or no access to eye clinics. 'I came across people who had been blind for many years and needed cataract surgery to restore their vision. Hopefully this will enable people to get the help they need as soon as possible, rather than suffering with preventable blindness for long periods of time,' he adds. He previously spent time in New York and Washington, USA, where he designed mobile phone applications for healthcare.

It is to be hoped that the right government officials, national and provincial, will take note of this quartet of healthcare innovators who have the products and tools to make their delivery task so much easier and cheaper. The private sector certainly is ...

\section{Chris Bateman \\ chrisb@hmpg.co.za}

\section{S Afr Med J 2015;105(5):334-336.} DOI:10.7196/SAMJ.9682

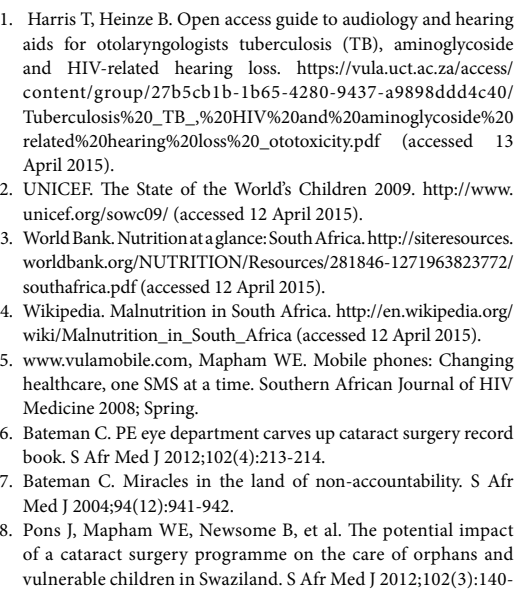
aids for otolaryngologists tuberculosis (TB), aminoglycoside and HIV-related hearing loss. https://vula.uct.ac.za/access/ content/group/27b5cblb-1b65-4280-9437-a9898ddd4c40/ Tuberculosis\%20_TB_,\%20HIV\%20and\%20aminoglycoside $\% 20$ related\%20hearing\%20loss\%20_ototoxicity.pdf (accessed 13 April 2015).

2. UNICEF. The State of the World's Children 2009. http://www. unicef.org/sowc09/ (accessed 12 April 2015)

3. World Bank. Nutrition at a glance: South Africa.http://siteresources. worldbank.org/NUTRITION/Resources/281846-1271963823772/ southafrica.pdf (accessed 12 April 2015)

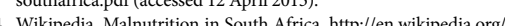
wiki/Man 5. www.vulamobile.com, Mapham WE. Mobile phones: Changing healthcare, one SMS at a time. Southern African Journal of HIV Medicine 2008; Spring.

6. Bateman C. PE eye department carves up cataract surgery record book. S Afr Med J 2012;102(4):213-214.

7. Bateman C. Miracles in the land of non-accountability. S Afr Med J 2004;94(12):941-942.

8. Pons J, Mapham WE, Newsome B, et al. The potential impact of a cataract surgery programme on the care of orphans and vulnerable children in Swaziland. S Afr Med J 2012;102(3):140- 